\title{
Indulgencia para todos, en Austria y Alemania
}

G Uando Manuel Eduardo de Gorostiza huyó a Inglaterra en 1823,
después de haber sido proscrito por Fernando VII, ya había
realizado muchas de las obras originales que le dieron lugar pro-
minente en la historia de la literatura española e hispanoamericana.
Sus traducciones posteriores, de obras dramáticas francesas y ale-
manas, hechas en México, no son muy conocidas, y el hecho de
que algunas de sus comedias originales fueron traducidas y repre-
sentadas en otros países, además de España y México, no se ha
mencionado hasta ahora. El éxito de una sola obra, Indulgencia para
todos, bastaría para dar idea del amplio círculo en que su labor fué conocida y estimada.

Por diversos caminos pudo haber llegado a Viena su obra. Estrenada en 1816 en el teatro del Príncipe, de Madrid, con gran éxito, fué representada varias veces durante las décadas subsecuentes, en España y en México. Futé traducida al francés y publicada en esa lengua en 1822; reimpresa en español, en París, el mismo año y en Bruselas en 1825, y además se hicieron de ella otras mu1chas ediciones españolas. Su inclusión, con un breve esbozo biográfico de su attor, en el Tesoro del Teatro Español (París, 1838, $\mathrm{v}$, 595-628), de Ochoa, la hizo aún más ampliamente conocida. ${ }^{1}$

No cabe la menor duda, sin embargo, acerca de cómo Heinrich Laube, novelista, autor y director del teatro Hofburg, en Viena (1848-1867), llegó a conocerla, pues él mismo ha dejado algunas notas sobre el incidente: 
Cierto día el actor Lussberger, durante un paseo por Viena, me dijo que Otto Prechtler le había hablado de una obra española y había mostrado una traducción de ella: ${ }^{3}$

- ¿Le interesó a usted?

-Sí. No precisamente la obra misma, sino el problema que allí se presenta.

Hallé lo mismo, después de haber oido la historia, y más tarde leí la traducción. El tema, o como dice Lussberger, el asunto, era estimulante: un joven, que permitió que sus virtudes hicieran de él un pedante, se ve colocado en una embarazosa situación y no puede ponerse a la altura de su pedante dogmatismo. Finalmente debe exclamar: "Indulgencia para todos". Este es también el título de esa obra española. Gorostiza es el autor."

Por entonces, Laube no sabía nada de Gorostiza; creyó que era joven y que su obra era nueva. Más tarde supo que el autor era un anciano, que había nacido en América y había envejecido en el servicio diplomático. Prestó a la obra mayor atención que la acostumbrada, antes de concluir que el elemento moral estaba en clla demasiado acentuado y el tono, en general, era demasiado sombrío, para que la aceptara el teatro alemán.

Sin dejarse convencer por este dictamen de Laube, Prechtler siguió trabajando en una traducción para la escena, en prosa alemana. Por último, la despojó de su ambiente español. La obra se había apoderado extrañamente de su imaginación; pero no solamente de la suya, porque Lussberger informa brevemente de la existencia de otra traducción alemana que él declaró más tarde poco satisfactoria. ${ }^{5}$

Laube rechazó la versión de Prechtler basándose principalmen te en que a dicha obra española le faltaba el encanto del verso original, para hacer resaltar toda su belleza. El traductor le recuerda que durante algunos años le había pedido obras en prosa. El director accede sonriente; pero insta al dramaturgo a que trate de hacerla, en este caso, en verso, y sugiere la Donna Diana de Schreyvogel, como posible modelo. Laube tuvo que admitir reflexivamente que tal trabajo tomaba tiempo y requería un tipo de habilidad creadorà más elevado aún que el suyo.

Algún tiempo después volvían a tratar el asunto; pero Prechtler no se mostró aún inclinado a hacer la traducción en verso. Durante la conversación, Laube comenzó a preguntarse a sí mismo por qué 
esa obra española no producía efecto alguno, en prosa alemana. No es una tragedia, tampoco una comedia, piensa; entonces pasa por su mente una idea: " $¿$ Por qué no una comedia?" Al instante contempla todo el drama desde nuevo punto de vista. Los dos principales actores del teatro del Burg surgieron ante él: Joseph Wagner, trágico y Karl Fichtner, comediante. Prechtler había escrito su versión pensando en Wagner; esto, reflexionó Laube, era un error; ya que a él le gustaría tratar el tema muy seria y dogmáticamente. Si la obra tenía que refundirse, el papel principal debía ser el de Fichtner. Pero antes de que llegara a ser una verdadera comedia, debería corregirla, cambiándole el ambiente español. $Y$ añadió Prechtler: "se deberá hacer otra obra, en la cual sólo se refleje la idea básica de Gorostiza." "Está bien", contestó Laube, y el tema fué abandonado.

Como obra teatral, sin embargo, empezó a tomar forma en la mente de Laube, y la siguiente vez que vió a Prechtler le expuso la dirección que debía tomar tanto la exposición como la motivación, y le anunció que ya estaba preparado para escribir el primer acto. La proposición fué del agrado de Prechtler, y de común acuerdo, decidieron escribir la comedia juntos. Laube escribiría el primer acto; Prechtler, después de varias discusiones, escribiría el segundo. Por desgracia, este arreglo se hizo al empezar las vacaciones de verano, precisamente antes de que ellos salieran de Viena; y durante esos meses, sin que pudieran tener ninguna entrevista, Prechtler escribió no solamente el segundo, sino también el tercero y el cuarto actos. El resultado de la colaboración fué que en todo lo hecho estaban completamente en desacuerdo. Laube había tenido la esperanza de evitar esto, revisando y recomponiendo acto por acto; entonces Prechtler, incapaz de seguir las sugestiones propuestas y aún bajo la influencia de su propio borrador inicial, únicamente había rozado superficialmente el tono más ligero de su nuevo primer acto. Aunque decepcionados, los dos comprendieron el fracaso de su tentativa de colaboración, y abandonaron la empresa.

Más tarde, después de que la versión de Prechtler se había borrado de su mente, Laube pensó en continuar su primer acto y trató de encontrar alguna manera de concluirlo de un modo diferente. Desde el principio ponían reparos a la trama de la obra. Pensó que si se podía eliminar aquello, sería posible hallar una 
nueva solución. Una comedia, reflexionó, debe desarrollarse naturalmente, basándose en dètalles de la vida diaria; si se encontraran esos detalles, los personajes por sí solos resolverían el enredo. Se le ocurrió que si el duelo ficticio tuviera algo de natural, pero con consecuencias inesperadas, esto podría distraer a los personajes de su propia intriga y el elemento cómico resaltaría a expensas de la didáctica. Pudiera infundírsele mayor realismo, y resultaría una obra probablemente más corta y por completo diferente. Tan pronto como lo pensó, lo llevó a cabo. Partiendo del duelo ficticio, Laube, sin consultar a Prechtler, escribió la obra hasta el final. El resultado fué una obra más corta, diferente y sin nada de ambiente español.

Un poco avergonzado - porque a su primer acto había añadido el segundo y el tercero- - envió el manuscrito a Prechtler, para que lo comentara.

El co-autor, que no había escrito ni una línea de esta versión, contestó simplemente que le había gustado la obra. En cuanto a la parte que le correspondía, pidió la mitad de los derechos de teatro, y cedió a Laube lo que produjera la obra impresa. Al efecto, con fecha 18 de enero de 1858, firmaron los dos, de común acuerdo, un convenio e inmediatamente después ambos se ocuparon en seleccionar el reparto $\mathrm{y}$ en otros detalles relativos a la representación.

Los cambios que hizo Laube en la obra, revelan no sólo su pericia como dramaturgo, sino especialmente su habilidad para descubrir y remediar los errores de estructura. La escena se traslada, de un pueblecito de Navarra, a las propiedades de Eisenstein, en las cercanías de Rüdesheim, a orillas del Rhin, y el ambiente es netamente alemán.

Todos los personajes tienen nombres alemanes. ${ }^{6}$ En el original español se sugiere un cambio de nombre: el de Catón, en vez de Severo. ${ }^{7} \mathrm{La}$ criada, que aparece frecuentemente en las obras españolas, y que en Indulgencia está considerada como de la familia -no solamente por su ama o señora, sino también por todos los miembros de la misma familia, y aun por el huésped-, se halla reemplazada por Bertha, la prometida de Siegfried, la cual ya aparece en la versión de Gorostiza, pero frecuentemente citada como Flora. La prometida, es decir, doña Tomasa, es más letrada y menos religiosa, más amante del deporte y más independiente. Se añaden otros dignos sirvientes y dos oficiosos representantes de la ley. Los 
cinco actos del original español (182 páginas, en la edición de Madrid de 1818), de cuatro a ocho escenas, se reducen a tres actos, de seis escenas cada uno (128 páginas, en la edición de Leipzig, 1875). En dos de estos actos, los acontecimientos de la obra original a través del duelo, se hallan tratados ampliamente.

En su tercer acto, Laube presenta las consecuencias judiciales del duelo, no como parte de la intriga proyectada, ${ }^{8}$ sino como un gran contratiempo para la familia de Eisenstein, así como para Catón, quien debido a eso precisamente renuncia a los principios de que había hecho alarde. Los largos discursos del original quedan también eliminados o abreviados, excepto el de Catón (acto II, escena IV) después de su brindis; éste subsiste como uno de los puntos culminantes de la obra.

Con mucha lentitud llegó la versión alemana a la forma en la cual se presentó finalmente. Fichtner fué el verdadero creador de Catón, y Laube le confió la mayor parte de los detalles.

Después de algunos meses de ensayo, criticando minuciosamente cada detalle, se presentó al fin al público la obra, con el título de Cato von Eisen. A pesar de las modificaciones hechas, en los programas figuró en nombre de Gorostiza, como autor de la obra.

Con objeto de dar a los críticos, al efectuarse la presentación, algún medio para que pudieran juzgar la obra en relación con el original, Laube pidió a Friedrich Halm que consiguiera una buena traducción en verso, al alemán, de Indulgencia para todos. Cumplió esta misión concienzudamente Hedwig Wolf, hija del famoso profesor de español Ferdinand Wolf, y su excelente versión fué puesta en manos de la crítica de Viena. Si su Cato von Eisen era un arreglo, adaptación o imitación de la obra de Gorostiza, o una producción original, Laube confesó que no podía determinarlo; dejó tal decisión a los críticos y a la posteridad.

La obra se adueñó inmediatamente de la imaginación del auditorio del Burg, y fué una de las más lucidas y estimadas en la temporada del año de 1858, en la cual se representó dieciocho veces. Su éxito se atribuye generalmente a la personalidad y arte histriónico de Fichtner.

La escena en que aparece borracho le valió frecuentes, calurosos aplausos; en las escenas de amor descubrió sus profundos sentimientos, y en el último acto, la forma en que el obstinado pedante, 
en conflicto con su corazón, realmente bondadoso, renuncia resueltamente a sus principios con firmeza defendidos hasta entonces y proporciona la conclusión de una comedia auténtica. Durante los últimos años, fué sin duda la mayor realización de Fichtner; pero fué también, como lo prueban los años subsecuentes, una de las obras maestras que produjo Laube.

La compañía era excelente, en todos sus aspectos, y fueron invariablemente admirables las representaciones de la obra. Después del primer año, Catón se repitió dos veces anualmente, durante los ocho años siguientes, y cada representación alcanzó la mayor calidad, gracias a nuevos y cuidadosos ensayos, por lo que la obra siguió siendo de las predilectas del exigente público del Burg.

Mientras tanto, las representaciones de Cato von Eisen no se limitaron a Viena. En Alemania misma el protagonista, Catón, fué interpretado admirablemente, aunque el elevado nivel de la representación vienesa no se alcanzó en parte alguna. En Berlín, fué un excelente Catón el actor Liedtke; y en Dresde, Emil Devrient; realmente, este celebrado actor cosechó tan abundantes y sostenidos aplausos, en tal papel, que lo escogió para interpretarlo en sus recorridos, como artista huésped; de este modo, la obra llegó a conocerse en muchos teatros, a los cuales de otra manera no habría llegado.

Al retirarse Fichtner, no por ello se olvidó la obra en Viena, como muchos creyeron que sucedería. Adolf Sonnenthal representó el mismo papel en el teatro del Burg, con igual aplauso. En el teatro de la Ciudad, del cual Laube llegó a ser director en 1872, con éxito un poco ménor, el comediante Tewele revivió a Catón, aunque a su actuación le faltaba el perfecto sentido artístico de Fichtner. En este papel, tanto la insistencia en su ideal como su enamoramiento fueron más débiles, $y$ por esta razón, la burla de que finalmente era víctima Catón resultaba menos dura. La representación, en conjunto, no fué, según Laube, inferior a las representaciones precedentes del teatro del Burg. En verdad, la obra fué una de las muy contadas a cuya popularidad se debió la salvación del teatro de la Ciudad, durante muchos años, antes de que se cerrara.

Diecisiete años después de la representación inicial de Catón en un escenario vienés, el texto alemán se imprimió; y tal publicación fué debida al prolongado éxito de la obra en el teatro de la Ciudad. 
En 1867, cuando por primera vez pensó en incluir a Catón entre sus obras dramáticas, Laube escribió un prólogo, en el cual nos cuenta la historia del origen de la obra, como aquí se detalla; a esto añadió, en diciembre de 1874 , una postdata en la cual continuó su historia hasta esa fecha. Durante el siguiente año, Cato von Eisen y la traducción hecha por Hedwig Wolf, de Indulgencia para todos, con el título equivalente, Nachsicht für Alle, se publicaron, con el prólogo de Laube, como puede verse en el íltimo volumen (XIII) de su Dramatische Werke (Leipzig, 1845-1875). En la segunda edición de las obras de Laube, tanto Catón como la traducción de Hedwig Wolf de Indulgencia para todos, aparecieron en el volumen XII, en 1907.

Así fué como durante más de medio siglo la obra de Gorostiza vivió y ganó laureles, en tierras alemanas, mientras en el Nuevo Mundo estaba casi olvidada.

\author{
J. R. SPEtL, \\ University of Teras.
}

\title{
$\mathrm{NOTAS}$
}

1 Adolf Shack, en su Geschinchte der dranatischen Literatur und Kunst in Spanien. (Berlín, 1845-1846, 3 vols.), trata de Gorostiza como dramaturgo, pero sin referirse especialmente a esta obra.

2 Un dramaturgo que dió al teatro local trabajos originales y adaptaciones y traducciones de obras extranjeras.

3 Esta puede haber sido la traducción francesa de Marie Aycard (París, 1822), incluída en el volumen LII del Répertoire des Théatres Etrangeres, Théatre espagnol, tomo 12, colección de obras extranjeras publicada por Brissot-Thivars.

4 Laube, H., Dramatische Werke. (Leipzig, Weber, 1875), xirr, (v). El asunto de esta obra consiste en demostrar, mediante un joven casi modelo, que la indulgencia para los errores de otros es también una virtud. Esto se logra durante su primera visita a la casa de su prometida, por medio de una maquinación planeada por la familia de la novia. En menos de un día esta imgen de perfección se enamora de la supuesta prometida de su futuro cuñado, se bate en duelo, pierde dinero que no le pertenece, permite que su amigo sea arrestado sin protestar siquiera, $y$ pretende ocultar estas faltas para conservar su reputación, hasta allí, sin mancha. Al darse cuenta de que su reputación está 
arruinada, se ve forzado a admitir, tristemente, que es una virtud soportar la debilidad humana.

5 Laube, H., Das Burgtheater. (Leipzig, 1891), 301.

6 ALEMAN

ESPAÑOL

Siegfried von Eisenstein.

Siegelinde von Eisenstein, su hija.

Bertha von Eltvill, su sobrina.

Siegmund von Eisenstein, su hijo.

Cato von Eisen.

Juez von Semmel.

Don Fermín de Peralta, padre de doña Tomasa.

Colasa, doncella de doña Tomasa.

Don Carlos, hijo de don Fermín.

Don Severo de Mendoza.

Don Pedro Arismendi, alcalde mayor.

Kreuzer, Comisario de Policía.

Kaspar, criado de von Eisen.

Gaspar, mayordomo de Mendoza.

Rocha?

Jacob $\}$ sirvientes de Eisenstein.

Andreas, guardián.

Hippolyt, cochero.

Weber, gendarme.

7

Quien trata

de encontrar en cada hombre

un Catón, mucho se engaña

a sí mismo, y mil pesares

para los demás prepara.

8 Esta debilidad ha sido señalada por muchos críticos españoles. Alberto Lista, ell su revista de la obra (El Censor, Madrid, 1822, 410-417) señala, entre sus defectos, la debilidad de que la doncella sea la que informe a Severo de que se conocen sus faltas y lo inste para que francamente las confiese. J. J. Mora, en una reseña del Teatro escogido de Gorostiza (Bruselas, 1825), en el Correo literario y politico de Londres, (Londres, 1826, 210-214), conenta: "El desenlace de esta pieza ha sufrido críticas muy severas y si mal no me acuerdo fué lo que menos gustó generalmente cuando salió por primera vez al público. En efecto, el autor no ha seguido la práctica general de imaginar un incidente imprevisto que descubre la trama, y que, en las conedias de carácter, ocasiona la conversión del protagonista." $\mathrm{P}$ (edro) de $\mathrm{M}$ (endívil), en su revista del mismo trabajo (Repertorio Americano. Londres, 1829), III, 78-93, describe la obra como "interesante, divertida, i si buena para leida, mejor aun para representada, a pesar de algunos descuidos en la disposición de la trama, i en su conducción i desenlaze." 